\title{
Economics and Management Laboratory Based on Constructivism
}

\author{
Yanhong Li ${ }^{*}$, a Bo Zhou ${ }^{\mathrm{b}}$, and Teng $\mathrm{Hu}^{\mathrm{c}}$ \\ University of International Business and Economics, Beijing 100029, P.R. China \\ aliyanhong11@me.com, b01620@uibe.edu.cn, cmisspast1223@gmail.com
}

Keywords: constructivism, educational ideology, learning space, pedagogy

\begin{abstract}
The rise of constructivism in the 20th century has had a profound impact on modern teaching models and learning space design. The emergence of the constructivist learning paradigm has shifted researchers' attention from teaching to learning. International research on learning spaces began in 2003. The popularity of the Internet has ushered in the spring of constructivist education. This paper mainly expounds the typical cases of the construction of economics and management laboratories of the University of International Business and Economics (UIBE) under the influence of the constructivist learning paradigm, discusses the changes in the learning space brought about by the different teaching objectives and teaching methods in the current international environment and national conditions, and expounds the transformation of learning space.
\end{abstract}

\section{Introduction}

Any teaching activities need to be carried out under certain time and space conditions. This certain time and space condition is tangible and intangible to form a specific learning environment. The construction and transformation of the learning environment is one of the foundations for the realization of the reform of teaching methods and the real breakthrough of educational reformation and the transformation of teaching methods in the context of educational reformation. After the introduction of the constructivist teaching concept in China in the 1990s, it caused the reflection and transformation of the entire teaching community on innovative education, the design of learning space also undergoes fundamental changes.

The University of International Business and Economics (UIBE) has been thinking about how to integrate information technology and education, seek breakthroughs in the design of learning space. UIBE began to carry out a large-scale learning space reform in 2012. After years of exploration, research and practice, the reform has been greatly recognized by brother universities. By optimizing the layout of learning spaces and integrating information technology, we can diversify the classroom teaching activities, promote the interaction between teachers and students, enrich the learning experience of students, provide conditions for the reform of school teaching methods, create a core competition for talent development in the 21st century. The term constructivism is the key to interpreting the ideas of the new learning space.

\section{About Constructivism and Basic Explanations for Learning}

There is a revolution in educational psychology that people call it different, but more often it is called a constructivist learning theory (Slavin, 1994). Constructivism develops from cognitivism and is a reflection of behaviorism and cognitivism. Developing in another direction that is more in opposition to objectivism (Jonassen, 1992). It was first proposed by the psychologist J. Piaget (1896-1980, Switzerland) in the 1950s. It not only believes that the teaching methods need to be improved, but even objective knowledge does not exist.

In the process of learning, the human brain does not passively learn and record the input information, but actively constructs the interpretation of the information. The learner actively chooses the information based on the content and tendency of the long-term memory and makes an inference. (M.C. Wittrock, 1983). From this basic point of view, today's constructivists place more 
emphasis on the role of informal empirical backgrounds formed in specific contexts, that is, non-structural empirical backgrounds, which are seen as the goals and foundations of construction. (Winograd, Flores, 1986; Duffy, Jonassen, 1991). Emphasize that learners do not develop a schema or propositional network that is extracted from the future to guide the activities in the learning process. On the contrary, the understanding of the concepts they form is rich and has an empirical background, thus facing new situations. It is possible to flexibly construct a schema that is brave enough to guide activities (Spiro, 1991).

The basic idea of constructivism is that the meaning of things does not exist independently of us, but from our construction (Brown, Collins Duguid, 1989a). Reflected in teaching, that is, learning is not the emphasis on knowledge, but the construction of knowledge, the process of constructing knowledge by the students themselves with the help of teachers. Teachers also changed from providers of knowledge to leaders of students. The basic idea of constructivist teaching theory is that everyone understands certain aspects of things in their own way. Teaching to enhance cooperation between students is the basis for seeing different views from him (Cunningham, 1992). Therefore, constructivism advocates teacher-centered self-directed learning and collaborative learning. The learning process emphasizes Meta learning, in which students self-manage the learning process. Constructivist teaching theory refers to communication to a very important position. From Socrates' elicitation teaching theory to Vygotsky's recent development zone theory, Oss's brainstorming theory, Mitchell's lifetime kindergarten theory, all exchanges, collaboration, discussion, and social interaction are the basic means of learning, prompting students to explore and discover actively.

In 2005, Dr. Kenn Fisher conducted a study on Linking Pedagogy and Space, pointing out that learning spaces are closely related to learning activities, specific learning spaces stimulate and promote specific learning activities. The constructivist teaching theory refers to communication to a very important position, which is reflected in the learning space. It is based on student and uses communication space and support space to create a platform for knowledge construction, encouraging and accepting students' autonomy and initiative. The communication space gives all kinds of learning spaces communication, which satisfies students' raw materials for constructing knowledge from other students, teachers and the environment. The support space provides data room, laboratory (physical space) and internet (virtual space).

The following will introduce the construction of economics and management Laboratory in UIBE based on the constructivist learning paradigm.

\section{The Main Thinking Framework for The Construction of Learning Space.}

Table 1. Thinking Model of the Learning Space Design

\begin{tabular}{|c|c|}
\hline Focus & Issues Considered During Project Formation and Design Phases \\
\hline Integrated & $\begin{array}{l}\text { What is the motivation for project development? } \\
\text { What is the goal I want to achieve? }\end{array}$ \\
\hline Education & $\begin{array}{l}\text { What are the current resources of the school and what needs to be increased? } \\
\text { How does space promote a type of learning that meets the talents of the new era? } \\
\text { How to evaluate the effect of the newly designed learning space? } \\
\text { How to implement the construction and use of the laboratory? }\end{array}$ \\
\hline Management & $\begin{array}{l}\text { How to effectively integrate multi-party resources to achieve effective learning space development? } \\
\text { What are the possible resistance and motivation? } \\
\text { In addition to the educational factors, what other reasons support the space design? } \\
\text { Do educational technicians, designers, teachers, students, and administrators need to participate in space } \\
\text { development and subsequent operations management? }\end{array}$ \\
\hline Space & $\begin{array}{l}\text { What is the space`s type and the corresponding teaching methods objectives? } \\
\text { What equipment and technology do you need for the corresponding type of space? }\end{array}$ \\
\hline Technology & $\begin{array}{l}\text { What is the motivation and resistance to use technology? } \\
\text { How does the role of technology in learning behavior records and skills development assessments? }\end{array}$ \\
\hline
\end{tabular}

Many universities and research institutions in North America, Europe and Australia have begun to promote the innovation of learning space, the development of information technology, the design of the learning space should consider the latest development of technology and pedagogy, requiring 
good communication and collaboration among the teachers, students, managers and architect technicians. In the design of the learning space, the general intentions put forward by the comprehensive experience and research of educational technicians, teachers and managers, the designers will solidify the ideas, improve the design details, and come up with specific plans for the participation of other educators. The design process requires a little more consideration for educational factors.

The thinking process of the space development process is showed in Table 1.

\section{Communication and Support Space.}

The laboratory corridor is equipped with a lounge chair. Each floor of the laboratory is equipped with a teacher's lounge. The financial laboratory also has a special leisure belt, with sofas in the middle of the work area. These leisure areas are a creative market. It emphasizes communication and encourages students and teachers from different majors to communicate. Open areas and reduced privacy also create a culture of rapid dissemination of ideas: once a group or member discovers the new world, everyone will soon learn and apply it.

At the same time, the financial laboratory has built a special teacher mobility intelligent research seminar room. Mobile workstations provide a good platform for encouraging collaborative innovation and facilitating communication between teachers. In this way, our different disciplines, different research directions and even teachers of different colleges, and even our visiting scholars, increase the probability of communication through the use of financial laboratory databases and the work of mobile stations. As well as convenience, a cooperative teaching organization is established to help teachers to quickly share, exchange and innovate in scientific research and teaching design.

The laboratory is equipped with cork board, which is convenient for teachers and students of different professions to publicize the needs of their research projects to invite interested teachers and students to participate, and to make other publicity posts to create a cultural atmosphere.

The support space is also reflected in the humanized design of the details. The learning space of the first phase of the development of the Zhixing Laboratory Building has been redesigned for the teacher's podium. The high and low platform design eliminates the traditional bulky steel platform, which satisfies the teacher's sitting and standing teaching scene. At the same time, the simple design of the intelligent central control panel allows the teacher to conveniently control the indoor projection, air condition, light and so on according to the needs of the teaching process without course interruption.

\section{Highly Flexible Space That Promotes Class Interaction.}

Most of the traditional classrooms are focusing on teacher give lectures and students just listening, the so called spoon-feed teaching method. The whole classroom is controlled by teachers, and students passively accept knowledge. With the development of multimedia teaching, the materials prepared by the teachers can even be used for many years. Students can easily obtain the PPT and have little motivation of taking notes in the class, let alone the understanding and digestion in time to seek interaction with teachers. The teachers become the single source of knowledge.

In the spatial layout of the newly-reformed computer laboratory, the tables and chairs of the large classrooms are placed horizontally, shortening the teacher-student distance, providing quick access for teachers to any student or group in the class, increasing the teacher-student interaction.

The new multimedia small classroom has got rid of the shackles of the traditional classroom fixed pattern. The learning chair is a movable and integrated seat. The chassis can be used to store schoolbags and sundries. The table can be used for books and laptops. The table and chairs can move flexibly and the table boards can splice freely. Compared with ordinary tables and chairs, it not only saves space but also is convenient. It constructs a flexible and efficient communication space for creative team practice activities, which can quickly switch between group discussions, lectures or traditional teaching modes, help team members focus on communication and innovation. This not only improve the effectiveness of teamwork and promote class interaction but also effectively 
transform a single spoon-feed teaching into a class that integrates the comprehensive teaching methods. There is no fixed platform design, teachers no longer have to be imprisoned at the podium, they can walk into the students to interact with the students as they like.

The discussion room in the financial laboratory uses a newly designed discussion table. Each discussion table is designed in U-shape, equipped with two display screens and each location has a VGA cable, which is convenient for the members of the discussion group to discuss freely and seamlessly. Projection on the display, quick sharing, equal exchange of ideas, and the use of university interaction to stimulate innovation. The chair of the discussion table can be raised and lowered, so that other people who come to participate in the discussion can communicate in parallel with the eyes of the sitting classmates without having to look up or lean over.

\section{Smooth Interaction Ensured by Effective Information Technology.}

Information technology equipment has become an indispensable tool for teachers. In the past decade, multimedia technology has actually affected the interactive nature of teaching. Iron podiums and fixed desktops and fixed microphones secure the teacher to the podium. Teaching interactions are less than in the absence of multimedia devices. The essence of the teaching process is a highly interactive process. Good teaching must involve students actively. High-quality teaching is inseparable from high-quality interaction. This interaction is not limited to the relationship between the student and the teacher, but also among students, between the student and the device, between the student and the content, and between the student and the classroom. The transformation of classrooms is based on enriching interactions, minimizing the cost of teaching interaction and maximizing the enthusiasm and initiative of students to participate in the teaching process.

The concept of intelligent management and the public resources of the school will enable the Collaborative Innovation Practice Center to conduct an open appointment management. For public seminars, the relatively independent collaborative innovation practice teaching environment is encouraged by groups, and students are encouraged to form groups to conduct various seminars, such as teaching seminars, team innovation practices, and mock interviews.

The learning space developed this time also has the function of being flexible and varied according to different usage requirements. A space often carries different courses and carries out different activities. Considering the limited characteristics of school space resources, the transformation of different modes, classrooms and teaching methods is simplified through the flexibility of furniture, information technology and space. Teachers and students can switch between computer labs and ordinary multimedia classrooms through the conversion of computer arms. Through the AD distribution technology to achieve the switching of different courses, multimedia courses, language courses and so on to achieve fixed and flexible, fully improve the space. Resource utilization providing adequate teaching service support.

In terms of projection technology, the laboratory not only adopts the traditional projector plus screen, but also uses Apple TV's mirror projection. As long as it is connected to the classroom's exclusive Wi-Fi, it cannot pass the traditional mode such as U disk and VGA cable. Wireless projection, convenient communication, mobile display can greatly facilitate the combination of classroom forms, further enhance interaction, and promote the sharing of classroom team resources.

The interactive discussion table of the Financial Insurance Financial Simulation Research Laboratory is equipped with specialized interactive equipment. Students`own wireless devices are easily projected onto the display device of the discussion table, group information sharing and collaboration, cooperation and discussion can be smoothly completed.

At present, the school has also begun to try to use technology to collect and analyze student behavior data and explore means of student skills training and evaluation. In the future, teachers' teaching evaluation and teaching diagnosis methods will have a great degree of breakthrough.

\section{User Data Feedback.}

We actively track the use of new design space. We see that the teaching methods of teachers are 
changing with the changing of teaching space. The forms of teaching activities are more diverse, teachers are more willing to communicate with students, and enhance interaction with students. Group discussions, scenario simulations, and results presentations are rich and varied. Teaching environment have played a key role in the reform of teaching methods.

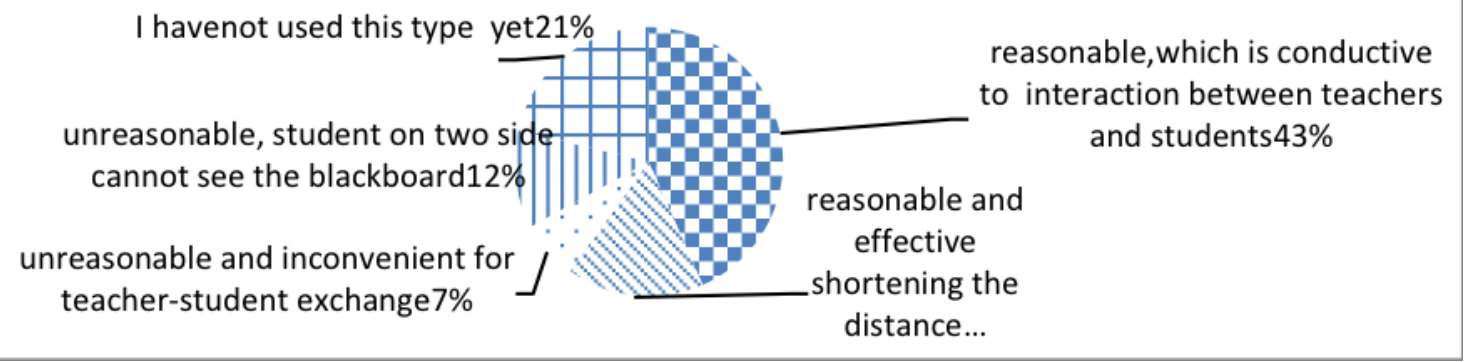

Fig 1. Do you think the classroom of the horizontal structure is reasonable?

Students use the web to search resources in class Use the movable table and chair to transform the teaching space Teacher teachers by PPT learn by playing games in class learn by simulation individual or group presentations Student group discussions Students cast their devices on the screen The teacher walked to the students

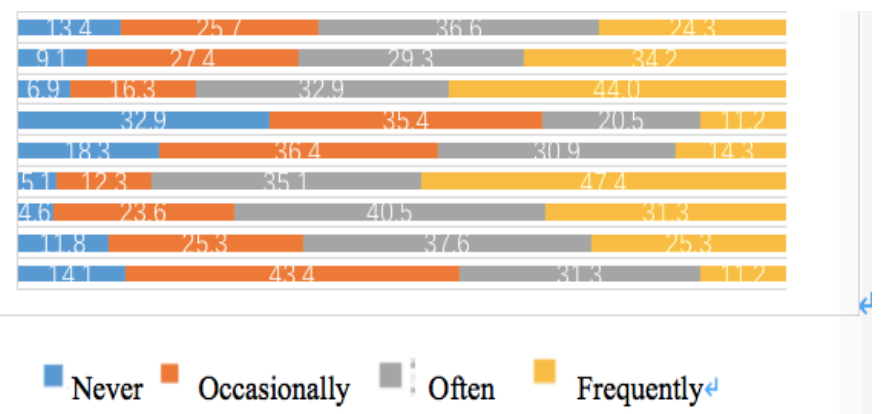

Fig 2. Behavior of teachers and students in a newly designed laboratory

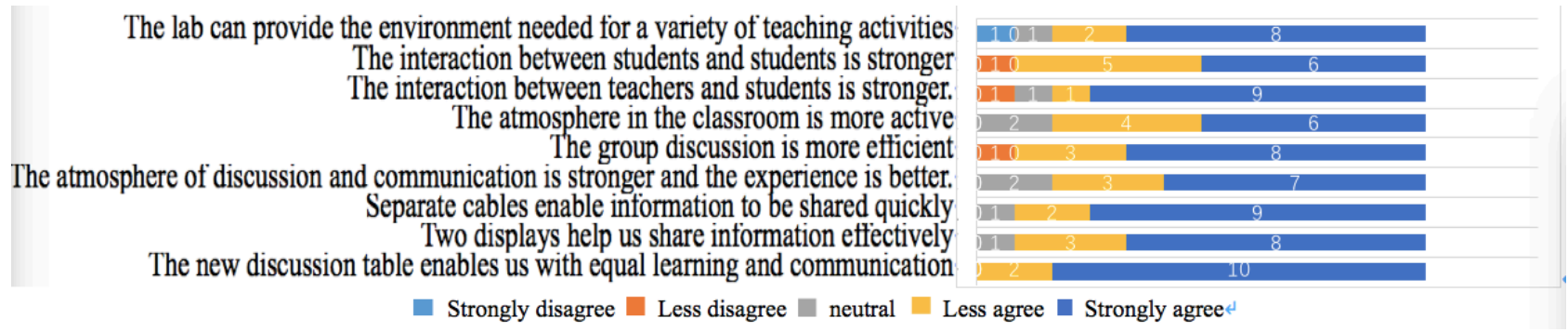

Fig 3. Student satisfaction of the Financial Innovation Laboratory

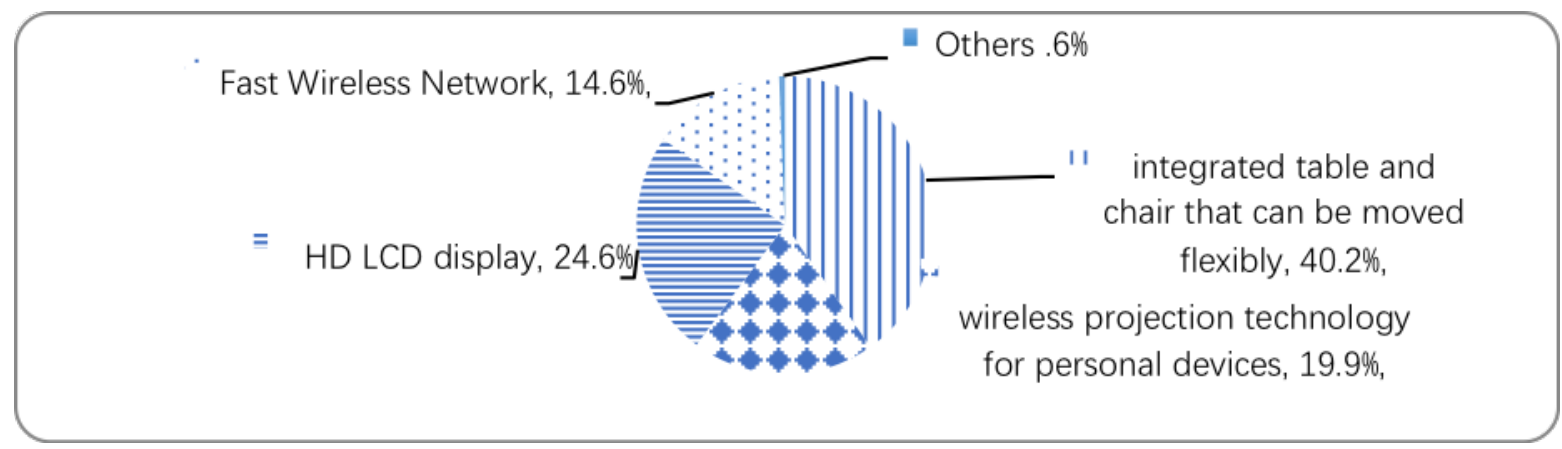

Fig 4. The reasons why you are willing or willing to attend a new lab.

The horizontal structure classroom is one of the highlights of the laboratory project. As is shown in Fig.1, most students think that such classroom structure is reasonable. It can effectively shorten the distance between teachers and students and is conducive to classroom interaction between teachers and students.

Fig. 2 show that in the newly designed laboratory, the forms of teaching activities are more diverse, and teachers are more willing to go to among students, enhance interaction with students. Group discussions, simulation, and group presentations are rich and varied.

Fig.3 shows the student satisfaction of the Financial Innovation Laboratory. The laboratory is well 
suited to the school's teaching method reform project. The group discussion is more efficient. The interaction in class is stronger, atmosphere in the class is more efficient and experience is better. Separate cables enable information to be shared quickly. The U-shape and stand-up height discussion table provides equal learning and communication.

The new space provides teachers and students with a new, functional and flexible teaching space. Students pay more attention to class, teachers and students have better interaction and students are more motivated to learn. Fig.4 shows that flexible mobile and integrated tables and chairs (40.2\%), high-definition LCD screen (24.6\%), wireless projection technology (19.9\%) and fast wireless network speed (14.6\%) are the main reasons to attend a new lab.

\section{Conclusion}

Constructivist learning and teaching perspectives are very instructive for our current teaching reforms. In the context of responding to the demands and challenges of talents in the new era, the reconstruction of learning space based on constructivism is an important breakthrough in the reform of teaching methods.

The large-scale collaboration and knowledge sharing in the Internet era has provided unprecedented convenience for constructivist self-directed learning. The hierarchy and boundaries among people are moving toward unity and ablation. The concepts of general education, cross-border design and so on have profoundly changed the organization and spatial mode of education. Under the constructivist teaching ideology, the teacher becomes the director, the student becomes the protagonist and the learning space becomes the stage for the student performance.

\section{Acknowledgement}

This work was financially supported by the Undergraduate Teaching Reform Project of University of International Business and Economics (X17729).

\section{References}

[1] D.J. Cunningham: Assessing Constructions and Constructing Assessments: A Dialogue. In T.M. Duffy \& D.H. Jonassen (Eds.): Constructivism and the Technology of Instruction: A Conversation. Lawrence Erlbaum Associates, Inc (1992).

[2] T.M. Duffy: Attempting to Come to Grips with Alterative Perspectives. In T.M. Duffy \& D.H. Jonassen (Eds.): Constructivism and the Technology of instruction: A Conversation. Lawrence Erlbaum Associates, Inc (1991).

[3] D.H. Jonassen: Evaluating Constructivistic Learning. In T.M. Duffy \& D.H. Jonassem (Eds): Constructivism and the Technology of Instruction: A Conversation. Lawrence Erlbaum Associates, Inc(1991).

[4] R.J. Spiro: Cognitive Flexibility, Constructivism, and Hypertext: Random Access Instruction for Advanced Knowledge Acquisition for ill-structured Domains. In T.M. Duffy \& D.H. Jonassen (Eds): Constructivism and the Technology of Instruction: A conversation. Lawrence Erlbaum Associates, Inc (1991).

[5] R. E. Slavin: Educational psychology: Theory and Practice(4th). Allyn and Bacon(1994).

[6] J.S. Brown, A. Collins and P. Duguid: Situated cognition and the culture of learning. Educational Researcher,18(1989), p.32-42.

[7] R.J. Osborne, M.C. Wittrock: Learning science: A generative process. Science Education, 67(4) (1983),p.489-508.

[8] Kenn Fisher: Linking pedagogy and space [EB/OL]. Information on http://www.eduweb.vic.gov.au/edulibrary/public/assetman/bf/Linking_Pedagogy_and_Space.pdf. 